\title{
Effect of Renoprotective Amino Acids and a Dipeptide on Disease Progression, Nutritional Status, and Blood-Serum Phosphate Concentration in Cats with Chronic Kidney Disease
}

\author{
JAMES D. ARCHER* \\ Applied Research Laboratory-Veterinary Studies Project, Villa Pompeii Campus, 4848 Olive Hill Road (28 Rolling \\ View), Fallbrook, CA 92028, USA.
}

\begin{abstract}
Low-protein, low-phosphorus therapeutic diets (TDs) are often recommended for cats (Felis catus) with chronic kidney disease (CKD) in an attempt to slow disease progression. Studies in humans with CKD reveal that dietary supplementation with certain amino acids slows or prevents time-related increases in blood-serum creatinine concentration ( $\mathrm{SCr}$ ) and phosphate concentration (PHOS). The objectives of this study were to assess the influence of a renoprotective amino acid and a dipeptide complex (AB070597) on disease progression, PHOS, and protein oxidation/nitrogen-balance in non-protein, non-phosphorus-restricted diet cats with CKD. The treatment group included 67 privately-owned domestic cats with $\mathrm{SCr}$ and clinical signs consistent with $\mathrm{CKD}$. A retrospective control group included 57 non-AB070597-treated CKD cats. Cats in the treatment group received 300-mg oral bi-daily doses of $\mathrm{AB} 070597$ for up to 104 weeks. $\mathrm{SCr}$ and $\mathrm{PHOS}$ were measured at approximate 12 -week intervals. Treated cats experienced significantly reduced $\mathrm{SCr}(\mathrm{mg} / \mathrm{dL})$ from baseline during all observation periods $(\mathrm{P} \leq 0.004)$, except week $12(\mathrm{P}=0.054)$. The overall least squares mean (LS-mean) difference between treatment and control groups was -0.5 $(\mathrm{P}<0.001)$. When International Renal Interest Society (IRIS) disease stage was expressed as LS-means change-frombaseline, treatment values were negative, whereas control values were positive, indicating a decline in stage for treatment and an increase for controls. The overall difference at 104 weeks for treatment was $-0.4(\mathrm{P}<0.001)$. Treatment group mean and median PHOS $(\mathrm{mg} / \mathrm{dL})$ declined from baseline $-1.3(\mathrm{P}<0.002)$ and $-0.2(\mathrm{P}<0.002)$, respectively, at 104 weeks, whereas control group mean and median values increased $0.14(\mathrm{P}<0.004)$ and $0.3(\mathrm{P}<0.002)$, respectively. Treatment group cats' body weights $(\mathrm{kg}$, standard deviation [SD]) remained stable: mean change $(0.0,0.75), \mathrm{P}<0.001$; while controls lost weight: mean change $(-0.9,1.07), \mathrm{P}<0.001$. Oral supplementation of renoprotective amino acids and a specific dipeptide prevented disease progression, maintained nutritional status, and preserved PHOS homeostasis in treated cats and may benefit the greater population of companion cats diagnosed with CKD.
\end{abstract}

Keywords | Cats, Chronic kidney disease, Supplement, Amino acid, Progression

Editor | Muhammad Abubakar, National Veterinary Laboratories, Islamabad, Pakistan.

Received | March 04, 2019; Accepted | March 25, 2019; Published | June 26, 2019

*Correspondence | James D Archer, Applied Research Laboratory-Veterinary Studies Project, Villa Pompeii Campus, 4848 Olive Hill Road (28 Rolling View), Fallbrook, CA 92028, USA; Email: jarcher@appliedresearchlaboratory.us

Citation | Archer JD (2019). Effect of renoprotective amino acids and a dipeptide on disease progression, nutritional status, and blood-serum phosphate concentration in cats with chronic kidney disease. Res. J. Vet. Pract. 7(2): 39-52.

DOI | http://dx.doi.org/10.17582/journal.rjvp/2019/7.2.39.52

ISSN (Online) | 2308-2798

Copyright (C) 2019 Archer et al. This is an open access article distributed under the Creative Commons Attribution License, which permits unrestricted use, distribution, and reproduction in any medium, provided the original work is properly cited.

\section{INTRODUCTION}

$\mathrm{T}$ he prevalence of $\mathrm{CKD}$ rises with age, and approximately 5\%, 7-10 years old, 10\%,11-14 years old, and $30 \%$ of cats over 14 years of age develop CKD (Polzin et al., 1992). The mean age at diagnosis is 12.8 years (Boyd et al., 2008); however, cats have been diagnosed with CKD as early as 9 months and as late as 22 years (DiBartola et al., 1987). The course of the disease is variable, with some cats progressing to end-stage within months while others survive for years (Chakrabarti et al., 2012). Medical consensus considers $\mathrm{CKD}$ progressive and irreversible, 
Table 1: IRIS ${ }^{a} \mathrm{CKD}^{\mathrm{b}}$ Disease Stages in Cats

\begin{tabular}{|c|c|c|c|}
\hline \multirow[t]{2}{*}{ Stage } & \multicolumn{2}{|c|}{ Serum Creatinine } & \multirow[t]{2}{*}{ Comments } \\
\hline & $\mathrm{mg} / \mathrm{dL}$ & umol/dL & \\
\hline Normal range & $0.6-2.2$ & $53-194$ & No clinical signs of renal disease. \\
\hline At risk & $<1.6$ & $<140$ & $\begin{array}{l}\text { No clinical signs of renal disease, but increased risk due to factors such as age, } \\
\text { breed, exposure to nephrotoxins, etc. }\end{array}$ \\
\hline 1 & $<1.6$ & $<140$ & $\begin{array}{l}\text { Non-azotemic, but has at least one renal abnormality such as proteinuria, low urine } \\
\text { specific gravity or abnormal imaging results. }\end{array}$ \\
\hline 2 & $1.6-2.8$ & $140-249$ & Mild azotemia, often with mild or absent clinical signs. \\
\hline 3 & $2.9-5.0$ & $250-439$ & Moderate azotemia. Extrarenal clinical signs may be present. \\
\hline 4 & $>5.0$ & $>440$ & Increasing risk of systemic clinical signs and uremic crises. \\
\hline
\end{tabular}

${ }^{\text {IIRIS }}=$ International Renal Interest Society; ${ }^{\mathrm{b}} \mathrm{CKD}=$ chronic kidney disease.

Source: http://www.iris-kidney.com/pdf/3 staging-of-ckd.pdf; accessed 24 May 2018.

thus treatments are supportive or palliative. Treatments may include hydration maintenance, calcium, vitamin D, erythropoietin supplementation; TDs, enteral phosphate binders, anti-hypertensive therapy, and histamine $\mathrm{H} 2$-receptor blockers to manage secondary gastritis. The IRIS developed guidelines to categorize the severity of CKD (IRIS, 2016). The initial assessment is based on at least 2 measurements of fasting $\mathrm{SCr}$, patient history, and the results of clinical examination. The IRIS stages are shown in Table 1.

Veterinarians often recommend TDs for cats with CKD. Restriction reduces PHOS, blood-urea nitrogen, and parathyroid hormone concentrations, and increases survival time in cats that accept the diet, when compared with cats on non-TDs (Elliot et al., 2000). Poor acceptance is common, however; with one study showing that $59.13 \%$ of cats rejected change from their former diet to TDs (Caney, 2017). TDs generally have decreased protein, phosphorus, increased carbohydrate, and variable fat content, compared with non-TDs.

A study by Salaun et al. (2017) confirmed an earlier finding by Hewson-Hughes et al. (2011) that a carbohydrate-consumption ceiling exists in cats which limits daily food intake based on daily carbohydrate intake; thereby creating deficits in protein and fat consumption, compared to their metabolic energy requirement, when fed high carbohydrate foods. Once they consumed food equivalent to $3 \mathrm{~g}$ carbohydrate $/ \mathrm{kg}$ body-weight/day, they stopped eating. The carbohydrate-consumption ceiling established by Hewson-Hughes et al. was higher at $4.1 \mathrm{~g}$ carbohydrate/ $\mathrm{kg}$ body-weight/day.

In a study by Bryan Kestenbaum et al. (2005) of humans with CKD, PHOS was independently and significantly related to mortality. For each $1 \mathrm{mg} / \mathrm{dL}$ PHOS increase, there was a significant $23 \%$ increased risk of death $(\mathrm{P}<0.001$, $95 \% \mathrm{CI}, 1.12-1.36)$. PHOS above the mid-range value of $3.5 \mathrm{mg} / \mathrm{dL}$ correlated with increased mortality risk, with an approximately linear relation for increased risk for each $0.5 \mathrm{mg} / \mathrm{dL}$ PHOS increase.

Cats with CKD that experience a PHOS increase of $1 \mathrm{mg} /$ $\mathrm{dL}$, within 1 year of diagnosis, have a $41 \%$ increased risk of progression to higher IRIS stages (Chakrabarti et al., 2012) and an $11.8 \%$ increase in the risk of death for the same increase over any time period. In a study by Boyd et al. (2008), PHOS was the only biochemical parameter that was predictive of survival.

Inorganic phosphate $(\mathrm{Pi})$ absorption and reabsorption/excretion in all mammals are controlled by $3 \mathrm{Na}$-dependent $\mathrm{Pi}$ cotransporter proteins $(\mathrm{NaPiIIb}$, which mediates absorption in the small intestines, and $\mathrm{NaPi}$-IIa and NaPiIIc, which control reabsorption/excretion in renal proximal tubules (Foster et al., 2006), so knowledge regarding PHOS homeostasis gained from studies in rodents and humans can apply to cats.

Regardless of the inciting cause, $\mathrm{CKD}$ evolves to progressive tubulointerstitial fibrosis accompanied by deteriorating renal function. L-carnosine, the dipeptide in AB070597, has been shown to increase bone morphogenetic protein-7 (BMP-7) gene expression in human periodontal ligament cells (Ito-Kato et al., 2004). Zeisberg et al. (2003) demonstrated that BMP-7 counteracts transforming growth factor-B1-induced epithelial-to-mesenchymal transition and reverses chronic kidney injury. Our laboratory organized an in vitro microarray experiment using human renal primary proximal tubule epithelial cells (hRPTEC) (feline cells were not available) that showed cells incubated with $\mathrm{L}$-carnosine at $1.763 \mathrm{ug} / \mathrm{mL}$ increased BMP-7 messenger ribonucleic acid (mRNA) expression 2.13-fold while cells incubated with AB070597 at $3.125 \mathrm{ug} / \mathrm{mL}$ showed a 3.29fold increase. L-carnosine blood-serum concentration in healthy cats is $10.17 \mathrm{ug} / \mathrm{mL}$ (Sabatino et al., 2013).

Studies of humans with CKD demonstrate that dietary supplementation with certain amino acids and keto-amino 
acids slows or prevents time-related $\mathrm{SCr}$ increase, disease progression, and significantly reduces PHOS in some patients (Yatzidis, 2004; Mitch et al., 1984). Further studies in humans and animals have determined that specific amino acids produce a protective effect on renal function; these include L-arginine (Reyes et al., 1994), L-aspartic acid (Tada et al., 2008), L-glutamic acid (Yatzidis, 2002), L-glutamine (Sadar et al., 2016), glycine (Yin et al., 2002), L-histidine (Watanabe et al., 2008), and the dipeptide L-carnosine ( $\beta$ alanyl-histidine) (Aldini et al., 2011).

AB070597 is a complex of these amino acids and dipeptide. A previous study of oral AB070597 supplementation to 27 cats with CKD showed a significant decrease in median $\mathrm{SCr}$ and lower median disease severity as assessed by IRIS Stage, compared with untreated controls (Archer, 2015). The objectives of this study were to assess the influence of the amino acids and dipeptide in AB070597 on disease progression, protein oxidation/nitrogen balance, and PHOS in cats with CKD fed non-protein and non-phosphorus-restricted diets.

\section{MATERIALS AND METHODS}

\section{CATS}

This study was open-ended. Qualified subjects entered as they became available from referring clinics; therefore, baseline and successive observation period (OP) times were asynchronous; thus, no relationship existed between the number of cats observed for any OP and survival or removal. Data collection extended to 104 weeks. The treatment group consisted of 67 privately-owned domestic cats that ranged in age from 4 to 21 years (median=14 years) and weighed $4.12(1.2) \mathrm{kg}$. Cats were neutered males (33, $49.3 \%)$ and spayed females $(34,50.7 \%)$. Breeds represented were Domestic Short Hair (51, 76.1\%), Domestic Medium Hair (6, 9.0\%), Domestic Long Hair (6, 9.0\%), and Exotic (4, 6.0\%). Treatment group cats included 27 (40.3\%) in Stage 2, 26 (38.8\%) in Stage 3, and 14 (20.9\%) in Stage 4. Owners provided informed consent before enrollment. Cats remained under the care of their owners and received standard care throughout the study, which exceeded requirements defined in United States Congressional Public Law 89-544 (Animal Welfare Act of 1966), including flea and tick prophylaxis, subcutaneous fluids, and antibiotics as prescribed by their supervising veterinarians. All cats had been fed commercial non-TDs before the study and continued their original diets so protein and phosphorus would not be restricted, which would have lowered amino acid and phosphorus intake from pre-study baseline values; as well as created a daily metabolic energy deficiency in some animals because of the carbohydrate-consumption ceiling. From within the United States, $46.7 \%$ and $73.3 \%$ of wet TDs ( $\mathrm{N}=15$; Salaun ceiling and Hewson-Hughes ceiling, respectively) and $100 \%$ and $100 \%$ of dry TDs,
( $\mathrm{N}=9$; Salaun ceiling and Hewson-Hughes ceiling, respectively) contain carbohydrate percentages that limit protein and fat intake, thus creating metabolic energy requirement deficiencies (Archer, unpublished work). Owners were instructed to notify Applied Research Laboratory of any diet change and were polled monthly for compliance verification. Cats were eligible for enrollment if serial $\mathrm{SCr}$ was persistently $\geq 2.3 \mathrm{mg} / \mathrm{dL}$ (or if serial $\mathrm{SCr}$ was $<2.3 \mathrm{mg} / \mathrm{dL}$ but incrementally increased over time and was $\geq 2.3 \mathrm{mg} / \mathrm{dL}$ at inclusion), and if history of clinical signs was consistent with CKD (e.g., chronic polyuria, polydipsia, or small kidneys on abdominal palpation). Cats with suspected or verified disease, including diabetes mellitus, neoplasia, bacterial pyelonephritis, systemic hypertension, uncontrolled hyperthyroidism, acute renal failure, or other comorbidities unrelated to CKD were excluded. Complete blood count, blood chemistry, and weight profiles were determined before or at enrollment to establish $\mathrm{SCr}$, PHOS, and weight baselines.

A retrospective control group of 57 non-treated CKD cats, that ranged in age from 3 to 20 years (median $=13$ years) and weighed 4.1 (1.6) kg, was selected from medical records at 5 participating clinics (A, B, C, D, E.). Cats and their respective IRIS stages were distributed at clinics as follows:

$A=20$ stage 2,4 stage 4

$B=7$ stage 2,4 stage 3,2 stage 4

$\mathrm{C}=6$ stage 2,4 stage 3

$\mathrm{D}=2$ stage 2,1 stage 4

$\mathrm{E}=4$ stage 2,3 stage 3

Control cats were neutered males $(23,40.4 \%)$, spayed females $(18,31.6 \%)$, intact males $(10,17.5 \%)$, and intact females $(6,10.5 \%)$. Breeds represented were Domestic Short Hair (43, 75.4\%), Domestic Medium Hair (1, 1.8\%), Domestic Long Hair (2, 3.5\%), and Exotic (11, 19.3\%). Control group cats included 39 (68.4\%) in Stage 2, 11 (19.3\%) in Stage 3, and 7 (12.3\%) in Stage 4.

\section{SupPlemenT}

Amino acids and dipeptide were purchased from $\mathrm{Nu}-$ triland Group, Inc. (Paramount, California, USA) and Dongyu USI (Irvine, California, USA), respectively. Each 300-mg dose included $25 \mathrm{mg}$ L-arginine, $50 \mathrm{mg}$ glycine, $50 \mathrm{mg}$ L-glutamine, $25 \mathrm{mg}$ L-histidine, $50 \mathrm{mg} \mathrm{L}$-aspartic acid, $50 \mathrm{mg} \mathrm{L}$-glutamic acid, and $50 \mathrm{mg} \mathrm{L}$-carnosine. Cats were dosed twice daily. Each dose was mixed with $1.5 \mathrm{~mL}$ of water and was given by syringe directly into the subject's mouth or sprinkled on a small amount of food.

\section{BoDy WEIGHT}

Body weights were recorded at entrance, at the last clinic visit, and at various times between. Control group cats' body weights were taken from their respective medical records. 
Table 2A: Data-Recording Example

\begin{tabular}{|c|c|c|c|c|c|c|c|c|c|c|c|}
\hline Entry Points (days) & & 0 & 1 & 2 & 3 & $>>>$ & 644 & week & & & \\
\hline Animal & & & & & & & & & & & \\
\hline 1 & $\begin{array}{l}\mathrm{SCr}^{\mathrm{a}} \text { or } \\
\mathrm{PHOS}^{\mathrm{b}}(\mathrm{mg} / \\
\mathrm{dL})\end{array}$ & & n.n & n.n & n.n & n.n & n.n & n.n & n.n & n.n & n.n \\
\hline 2 & $"$ & & & & & & & n.n & n.n & n.n & n.n \\
\hline 3 & $"$ & & & & & n.n & n.n & n.n & n.n & n.n & n.n \\
\hline 4 & $"$ & & n.n & n.n & n.n & n.n & n.n & n.n & n.n & n.n & n.n \\
\hline 5 & $"$ & & & n.n & n.n & n.n & n.n & n.n & n.n & n.n & n.n \\
\hline 6 & $"$ & & n.n & n.n & n.n & n.n & n.n & n.n & n.n & n.n & n.n \\
\hline 7 & $"$ & & & & & & n.n & n.n & n.n & n.n & n.n \\
\hline 8 & $"$ & & & n.n & n.n & n.n & n.n & n.n & n.n & n.n & n.n \\
\hline 9 & $"$ & n.n & n.n & n.n & n.n & n.n & n.n & n.n & n.n & n.n & n.n \\
\hline 10 & $"$ & & & n.n & n.n & n.n & n.n & n.n & n.n & n.n & n.n \\
\hline 11 & $"$ & & & n.n & n.n & n.n & n.n & n.n & n.n & n.n & n.n \\
\hline 12 & $"$ & n.n & n.n & n.n & n.n & n.n & n.n & n.n & n.n & n.n & n.n \\
\hline 13 & $"$ & & n.n & n.n & n.n & n.n & n.n & n.n & n.n & n.n & n.n \\
\hline
\end{tabular}

N...67

Entry points for each animal (Table 2A) were translated to Synchronized-Baseline Cohorts (Table 2 B).

${ }^{\mathrm{S}} \mathrm{SCr}=$ blood-serum creatinine concentration; ${ }^{\mathrm{b}} \mathrm{PHOS}=$ blood-serum phosphate concentration.

Table 2B: Translation to Synchronized-Baseline Cohorts

\begin{tabular}{|c|c|c|c|c|c|c|c|c|c|c|c|}
\hline Observation Period (weeks) & & 0 & 12 & 24 & 36 & 48 & 60 & 72 & 84 & 96 & 104 \\
\hline \multicolumn{12}{|l|}{ Animal } \\
\hline 1 & $\begin{array}{l}\mathrm{SCr}^{\mathrm{a}} \text { or } \\
\mathrm{PHOS}^{\mathrm{b}} \\
(\mathrm{mg} / \mathrm{dL})\end{array}$ & n.n & n.n & n.n & n.n & n.n & n.n & n.n & n.n & n.n & n.n \\
\hline 2 & $"$ & n.n & n.n & n.n & n.n & & & & & & \\
\hline 3 & $"$ & n.n & n.n & n.n & n.n & n.n & n.n & n.n & n.n & & \\
\hline 4 & $"$ & n.n & n.n & n.n & n.n & n.n & n.n & n.n & n.n & n.n & n.n \\
\hline 5 & $"$ & n.n & n.n & n.n & n.n & n.n & n.n & n.n & n.n & & \\
\hline 6 & $"$ & n.n & n.n & n.n & n.n & n.n & $\mathrm{n} . \mathrm{n}$ & n.n & n.n & n.n & \\
\hline 7 & $"$ & n.n & n.n & n.n & n.n & n.n & & & & & \\
\hline 8 & $"$ & n.n & n.n & n.n & n.n & n.n & n.n & n.n & n.n & & \\
\hline 9 & $"$ & n.n & n.n & n.n & n.n & n.n & n.n & n.n & n.n & n.n & n.n \\
\hline 10 & $"$ & n.n & n.n & n.n & n.n & n.n & n.n & n.n & n.n & n.n & n.n \\
\hline 11 & $"$ & n.n & n.n & n.n & n.n & n.n & n.n & n.n & n.n & & \\
\hline 12 & $"$ & n.n & n.n & n.n & n.n & n.n & n.n & n.n & n.n & n.n & n.n \\
\hline 13 & $"$ & n.n & n.n & n.n & n.n & n.n & n.n & n.n & n.n & n.n & n.n \\
\hline
\end{tabular}

N...67

\begin{tabular}{|c|c|c|c|c|c|c|c|c|c|c|}
\hline Example Population & 13 & 13 & 13 & 13 & 12 & 11 & 11 & 11 & 7 & 6 \\
\hline Treatment Pop ${ }^{c}$ & 67 & 67 & 59 & 51 & 45 & 39 & 32 & 31 & 23 & \\
\hline
\end{tabular}

${ }^{a} \mathrm{SCr}=$ blood-serum creatinine concentration; ${ }^{\mathrm{b}} \mathrm{PHOS}=$ blood-serum phosphate concentration; ${ }^{\mathrm{c}} \mathrm{Pop}=$ Population.

Blood Sample Collection

A blood sample (2.0-3.0 mL) was collected from the jug- ular or saphenous vein at each regularly-scheduled clinic visit and placed into a serum-separator tube. The whole

June 2019 | Volume 7 | Issue 2 | Page 42 
blood sample was allowed to clot at room temperature and then centrifuged. Serum was separated and dispensed into a labelled transport tube. Each sample was sent to a local veterinary diagnostic reference laboratory (Antech Diagnostics, Headquarters, Irvine, California, USA or Idexx Laboratories, Headquarters, Westbrook, Maine, USA) for $\mathrm{SCr}$ and $\mathrm{PHOS}$ analysis.

\section{Laboratory Measurements}

$\mathrm{SCr}$ and PHOS were measured approximately every 12 weeks, up to 104 weeks or death, whichever occurred first. Measurements were performed at Idexx or Antech laboratories using an Olympus AU2700 Chemistry Analyzer and Beckman-Coulter AU5431 Chemistry Analyzer, respectively.

$\mathrm{SCr}$ and PHOS coefficients of variation (CV), as determined by Idexx Laboratories, were 3.33\%, 1.88\% and $3.51 \%, 3.08 \%$ (low end, high end of normal range), respectively; and less than 3\% for within-run samples at Antech Diagnostics, with a total precision of less than $5 \%$.

Control group $\mathrm{SCr}$ and $\mathrm{PHOS}$ analyses were also performed by Antech Diagnostics and Idexx Laboratories, except for 1 clinic that used in-house instrumentation supplied by Antech Diagnostics. Some laboratory reports were more than 4 years old, so the $\mathrm{CV}$ of the instrumentation used then is not known.

\section{BMP-7 MRNA EXPRESSION AND HRPTEC Viability Assays}

BMP-7 mRNA expression and hRPTEC viability assays for L-carnosine and AB070597 were performed by Cyprotex US, LLC, Watertown, MA 02472, USA. hRPTEC (Catalog \#: CC-2553) and Renal Epithelial Cell Bullet$\mathrm{Kit}^{\mathrm{TM}}$ (Catalog \#: CC-3190) were purchased from Lonza Walkersville, Inc., Walkersville, Maryland 21793, USA.

\section{BMP-7 MRNA EXPRESSION ASSAY}

Cells were cultured at $37^{\circ} \mathrm{C}, 5 \% \mathrm{CO} 2$ in renal epithelial cell growth medium, and passaged to 296 -well plates with a density of 4000 cells/well. After $24 \mathrm{~h}$ culture, varying concentrations of L-carnosine and AB070597 were added to each well and incubated for 6 days. Total RNA was extracted from hRPTEC using MagMax ${ }^{\mathrm{TM}}$-96 Total RNA Isolation Kit (ThermoFisher Scientific, Waltham, MA, USA). Complementary deoxyribonucleic acid (cDNA) was synthesized from total RNA with High Capacity RNA-to-cDNA Kits and a Veriti thermal cycler (ThermoFisher, Waltham, MA, USA). Real-time-quantitative PCR (RT-qPCR) was performed in Applied Biosystems Real-Time Quantitative polymerase chain reaction system (Thermo Fisher, Waltham, MA, USA). Expression of BMP-7 mRNA in treated cells was determined by RT-qPCR and compared with reference vehicle treated
hRPTEC. Peptidylproprolyl isomerase-A was used as an internal control.

\section{HRP'TEC VIABILITY AsSAY}

hRPTEC were plated on 384-well tissue culture treated polystyrene plates at $1.5 \times 10^{\wedge} 4$ cells. After overnight incubation at $37^{\circ} \mathrm{C}$, cells were dosed with $\mathrm{AB} 070597$ in a range of concentrations and incubated for $72 \mathrm{~h}$ at $37^{\circ} \mathrm{C}$. Cell viability was measured using the Promega Cell Titer 96 Non-Radioactive Cell Proliferation Assay (MTT) kit (Promega Corporation, Madison, WI, USA) by adding dye solution to each well and incubating for $3 \mathrm{~h}$ at $37^{\circ} \mathrm{C}$. After incubation, Promega Solubilization Solution/ Stop Mix was added to each well. Plates were incubated at $37^{\circ} \mathrm{C}$ for $1 \mathrm{~h}$ and mixed on a plate shaker for 10 minutes. Spectrophotometric absorbance was read at $370 \mathrm{~nm}$. The IC50 was calculated using GraphPadPrism (GraphPad Software, San Diego, CA, USA).

\section{Statistical Analysis}

Baseline (time 0) was the moment each cat entered the study. $\mathrm{SCr}$ and PHOS measurements were assembled into synchronized-baseline OP cohorts to adjust for asynchronous baseline entry dates, with the result that earlier OP cohorts included more cats than later cohorts, as shown in Table 2. Table 3 shows the number of treatment and control cats, versus length $(\mathrm{OPs})$ of observation.

Table 3: Number of Cats vs. Time Observed*

\begin{tabular}{|lll|}
\hline OP (weeks) & $\begin{array}{l}\text { Number of Cats } \\
\text { Control } \\
\text { Cats Observed }\end{array}$ & $\begin{array}{l}\text { Treatment } \\
\text { Cats Observed }\end{array}$ \\
\hline 0 Baseline & 57 & 67 \\
\hline 12 & 57 & 67 \\
\hline 24 & 57 & 59 \\
\hline 36 & 53 & 51 \\
\hline 48 & 51 & 45 \\
\hline 60 & 39 & 39 \\
\hline 72 & 34 & 32 \\
\hline 84 & 31 & 31 \\
\hline 96 & 24 & 23 \\
\hline 104 & 19 & 18 \\
\hline
\end{tabular}

*Declining numbers at increasing observation periods do not correlate with removal or survival but result from an open-ended study design with asynchronous entry dates.

IRIS Stage data were analyzed by converting $\mathrm{SCr}$ measurements to disease stages: Stage $1(\mathrm{SCr}<1.6 \mathrm{mg} / \mathrm{dL})$, Stage 2 (SCr, $1.6-2.8 \mathrm{mg} / \mathrm{dL})$, Stage 3 (SCr, 2.9-5.0 mg/ $\mathrm{dL})$ and Stage $4(\mathrm{SCr}>5.0 \mathrm{mg} / \mathrm{dL})$.

Data for SCr and IRIS stage were analyzed using the same method. For each endpoint, the change-from-baseline val- 
ue was calculated for each OP as Week N-Week 0. Descriptive statistics were calculated by treatment and OP for each endpoint and for the change-from- baseline values for each endpoint. For each endpoint, the change-from-baseline values were modeled using a repeated measure analysis of covariance model, with an autoregressive first-order covariance structure. The following covariates were evaluated for inclusion in the repeated measures model: study (secondary-analysis data, included in Archer (2015), versus data from the current study), age, baseline value, gender, sterilized (spayed or neutered versus intact), and breed. The fixed effects for treatment, time, and treatment by time interaction were included in the model. LS-means for treatment and control SCr and IRIS stage change-from-baseline, for each OP, along with the $95 \%$ confidence intervals (CI) for the LS-means, were calculated. The same statistics for overall treatment over 104 weeks were calculated. In addition, the differences in LS-means between treatment and control for each OP and over the entire 104-week treatment period were determined, along with the corresponding 95\% CIs and P-values for the differences. In addition, the counts and percentages for each IRIS stage for each OP were calculated for treatment and control groups. The P-value from the Cochran-Mantel-Haenszel (CMH) statistic, testing the alternative hypothesis that there was a linear association between treatment and stage, was calculated by OP. Normality assumptions were evaluated for each endpoint and, if the assumptions appeared violated, a sensitivity analysis was conducted using a ranked analysis of variance model like the original model used. The difference between these two models was that the changefrom-baseline was ranked within OP and then the model was fit on these ranked values. A two-sided, 2-sample t-test, with Satterthwaite approximation for unequal variances, was employed to compare the change-from-baseline body weights between treatment and controls. Treatment and control PHOS change-from-baseline were analyzed with the Wilcoxon Signed Rank Test. Statistical power for SCr LS-means change-from-baseline and IRIS LSmeans stage change-from baseline at each OP was calculated from control and treatment means, sampling ratio, and pooled standard error of mean (SEM). Analyses were conducted using SAS Institute, Inc. 9.4 analytics software (SAS Institute Inc., Cary, NC, USA) at significance level 0.05. AB070597 and L-carnosine induced BMP-7 mRNA fold-change in hRPTEC cells were analyzed with Applied Biosystems, QuantStudio Real-Time PCR Software (ThermoFisher Scientific, Waltham MA, USA).

\section{RESULTS}

Results are reported as mean (SD); LS-mean (SEM); median (minimum, maximum).

\section{$\mathrm{SCR}$}

Mean SCr was $4.2(2.66) \mathrm{mg} / \mathrm{dL}$ at week 0 for treatment cats, and $2.9(0.89) \mathrm{mg} / \mathrm{dL}$ for control cats. Mean $\mathrm{SCr}$ was lower in the treatment group, when compared with controls, at all OP, from week 12 to week 104. Values are plotted in Figure 1 and Table 4. Treated cats exhibited significantly reduced $\mathrm{SCr}$ from baseline at all $\mathrm{OP}(\mathrm{P}<0.001$ at $7 \mathrm{OP}, \mathrm{P}<0.004$ at $1 \mathrm{OP})$, except for week $12(\mathrm{P}=0.054)$. The overall difference at week 104 , between treatment group and controls, was -0.5 (CI: $-0.8,-0.2 ; \mathrm{P}<0.001$ ). There were some OPs where underlying normality assumptions may have been violated so a sensitivity analysis was performed on the ranked data. There was a significant difference for ranked data at all OPs including week 12. Thus, the data suggest that treatment significantly lowered $\mathrm{SCr}$ as compared with no treatment. The SCr LS-mean change-from-baseline over time is shown in Figure 2 and Table 5.

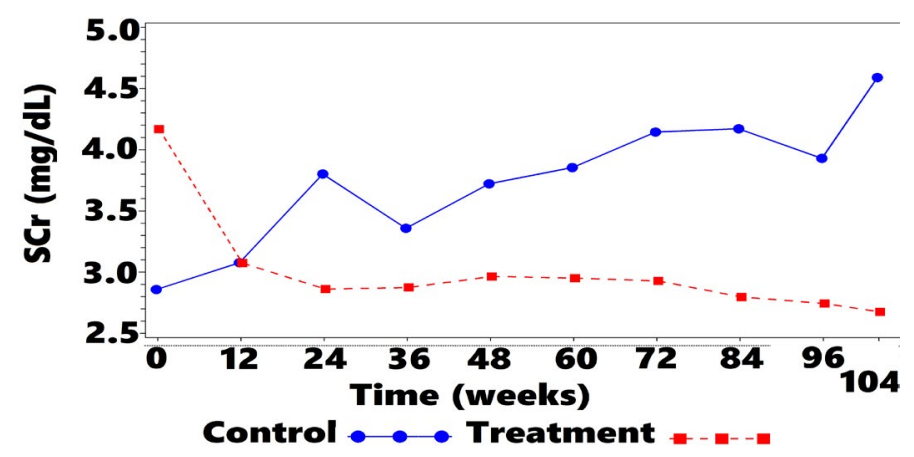

Figure 1: Mean $\mathrm{SCr}^{\mathrm{a}}$ vs. Time

${ }^{\mathrm{S}} \mathrm{SCr}=$ blood-serum creatinine concentration.

Table 4: Mean $\mathrm{SCr}^{\mathrm{a}}$ vs. Time

\begin{tabular}{llll}
$\begin{array}{l}\text { OP } \\
\text { (weeks) }\end{array}$ & \multicolumn{3}{l}{$\mathbf{S C r}(\mathbf{m g} / \mathbf{d L})$ mean $\left(\mathbf{S D}^{\mathrm{b}}\right)$} \\
\hline 0 & Control & Treatment & n-Treatment/Control \\
\hline 12 & $2.9(0.89)$ & $4.2(2.66)$ & $67 / 57$ \\
24 & $3.1(0.93)$ & $3.1(1.31)$ & $67 / 57$ \\
36 & $3.8(3.61)$ & $2.9(0.97)$ & $59 / 57$ \\
48 & $3.4(1.14)$ & $2.9(0.91)$ & $51 / 53$ \\
60 & $3.7(1.63)$ & $3.0(0.92)$ & $45 / 51$ \\
72 & $4.9(1.97)$ & $3.0(0.95)$ & $39 / 39$ \\
84 & $4.2(2.58)$ & $2.9(0.98)$ & $32 / 34$ \\
96 & $3.9(2.06)$ & $2.8(0.97)$ & $31 / 31$ \\
\hline 104 & $4.6(2.67)$ & $2.7(0.87)$ & $23 / 24$ \\
${ }^{a} \mathrm{SCr}=$ blood-serum creatinine concentration; \\
${ }^{\mathrm{b} S D}=$ standard deviation
\end{tabular}

\section{OPs AND IRIS DISTRIBUTION}

Mean IRIS Stage for treated cats was $2.8(0.76)$ and 2.3 $(0.68)$ at weeks 0 and 104 , respectively (Figure 3$)$. Stage 2 , 3 , and 4 cats were observed for 75 (32), 65 (34), and 39 (33) weeks, respectively (data not shown). 
Table 5: $\mathrm{SCr}^{\mathrm{a}} \mathrm{LS}-\mathrm{Mean}{ }^{\mathrm{b}}$ Change-from-Baseline vs. Time

\begin{tabular}{|c|c|c|c|c|c|}
\hline \multirow[t]{2}{*}{ OP (weeks) } & \multicolumn{2}{|c|}{ LS-Mean (SEM') } & \multirow[t]{3}{*}{$\mathbf{P}$} & \multirow{2}{*}{$\begin{array}{l}\text { n-Treatment/ } \\
\text { Control }\end{array}$} & \multirow{2}{*}{$\begin{array}{l}\text { Statistical Power } \\
\text { (\%) }\end{array}$} \\
\hline & Control & Treatment & & & \\
\hline 0 & & & & $67 / 57$ & \\
\hline 12 & $0.0(0.21)$ & $-0.5(0.20)$ & 0.054 & $67 / 57$ & 40.2 \\
\hline 24 & $0.7(0.21)$ & $-0.6(0.21)$ & $<0.001$ & $59 / 57$ & $>99$ \\
\hline 36 & $0.4(0.22)$ & $-0.5(0.22)$ & 0.004 & $51 / 53$ & 81.8 \\
\hline 48 & $0.7(0.22)$ & $-0.4(0.23)$ & $<0.001$ & $45 / 51$ & 92.8 \\
\hline 60 & $0.9(0.25)$ & $-0.4(0.25)$ & $<0.001$ & $39 / 39$ & 95.3 \\
\hline 72 & $1.2(0.27)$ & $-0.4(0.28)$ & $<0.001$ & $32 / 34$ & 98.2 \\
\hline 84 & $1.2(0.28)$ & $-0.5(0.28)$ & $<0.001$ & $31 / 31$ & 98.8 \\
\hline 96 & $1.2(0.32)$ & $-0.5(0.32)$ & $<0.001$ & $23 / 24$ & 95.7 \\
\hline 104 & $1.7(0.36)$ & $-0.6(0.38)$ & $<0.001$ & $18 / 19$ & 98.3 \\
\hline
\end{tabular}

${ }^{a} \mathrm{SCr}=$ blood-serum creatinine concentration; ${ }^{\mathrm{b}} \mathrm{LS}-\mathrm{Mean}=$ least squares mean; ${ }^{\mathrm{c} S E M}=$ standard error of mean.

Mean IRIS Stage for controls was $2.3(0.57)$ and $2.9(0.88)$ at weeks 0 and 104, respectively (Figure 3). Stage 2,3, and 4 cats were observed for 80 (27), 66 (28), and 65 (57) weeks, respectively (data not shown).

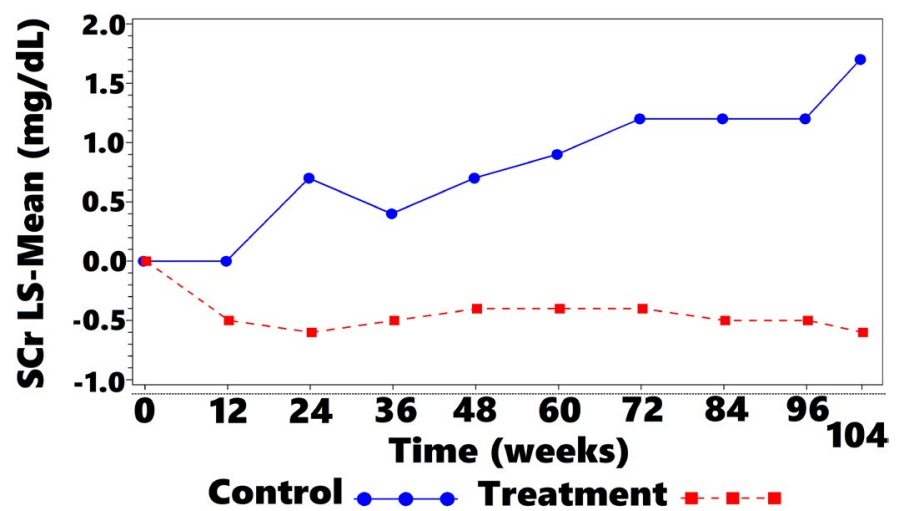

Figure 2: $\mathrm{SCr}^{\mathrm{a}}$ LS-Mean ${ }^{\mathrm{b}}$ Change-from-Baseline vs. Time

${ }^{\mathrm{a}} \mathrm{SCr}=$ blood-serum creatinine concentration; ${ }^{\mathrm{b}} \mathrm{LS}-\mathrm{Mean}=$ least squares mean.

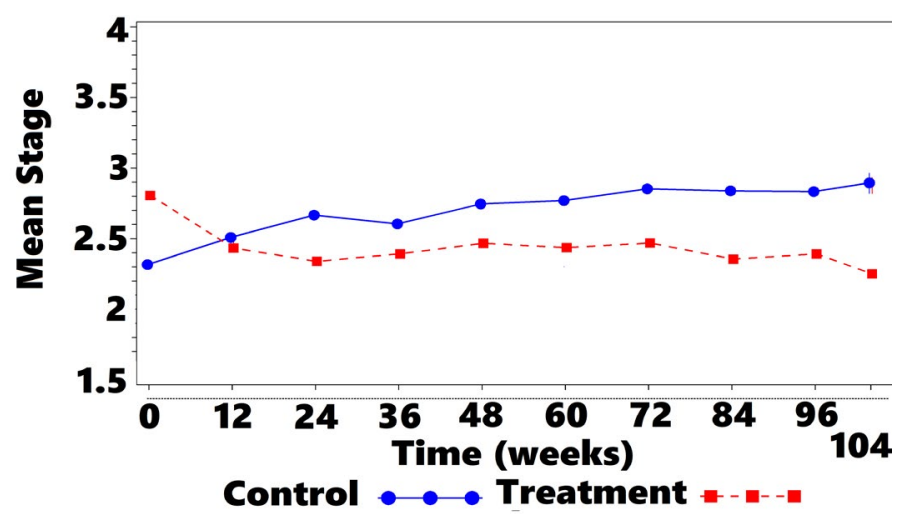

Figure 3: Mean IRIS ${ }^{a}$ Stage vs. Time

aIRIS = International Renal Interest Society.

\section{IRIS STAGE}

A comparison of averages showed that treated cats started at a numerically higher mean $\mathrm{SCr}$ and IRIS stage compared with controls. At week 12, treatment group stage declined whereas control group values increased (Figure 3). As time progressed, a gradual shift in the treatment group to lower mean IRIS stage compared with controls was observed. A CMH statistic test for linear association between treatment and reduced disease stage was significant at baseline, with the treatment group having higher stage values than the control group. At weeks 24, 48, 60, 72, 84, 96 , and 104 a significant linear association was observed between treatment and disease stage, with lower disease stage values observed in the treated cats compared with controls (Table 6).

Table 6: $\mathrm{CMH}^{\mathrm{a}}$ Test for Linear Association of Decreased Disease Stage with Treatment vs. Time

\begin{tabular}{ll} 
OP (weeks) & $\mathbf{P}$ \\
0 Baseline & $<0.001$ \\
\hline 12 & 0.495 \\
24 & 0.009 \\
36 & 0.091 \\
48 & 0.042 \\
60 & 0.033 \\
72 & 0.023 \\
84 & 0.004 \\
96 & 0.019 \\
104 & 0.025 \\
\hline
\end{tabular}

${ }^{a} \mathrm{CMH}=$ Cochran-Mantel-Haenszel.

When IRIS Stage was expressed as LS-mean changefrom-baseline, weeks $12,24,36,48,60,72,84,96$, and 104 showed significant reductions $(\mathrm{P}=0.006$ at week 12 , $\mathrm{P}<0.001$ weeks 24 to 104 ) as shown in Figure 4 and $\mathrm{Ta}-$ ble 7 . The overall difference at week 104 , between treatment and controls was -0.2 (CI: $-0.3,-0.1 ; \mathrm{P}<0.001)$. The treated group showed negative LS-mean change in IRIS 
Table 7: IRIS ${ }^{\mathrm{a}}$ LS-Mean ${ }^{\mathrm{b}}$ Stage Change-from-Baseline vs. Time

\begin{tabular}{llllll} 
OP (weeks) & \multicolumn{2}{l}{ Least Squares Mean (SEM) } & P & n-Treatment/Control & Statistical Power (\%) \\
\cline { 3 - 4 } & Control & Treatment & & \\
0 & & & & \\
12 & $0.1(0.08)$ & $-0.2(0.07)$ & 0.006 & $67 / 57$ & 79.9 \\
24 & $0.3(0.08)$ & $-0.3(0.08)$ & $<0.001$ & $59 / 57$ & $>99$ \\
\hline 6 & $0.3(0.08)$ & $-0.2(0.08)$ & $<0.001$ & $51 / 53$ & $>99$ \\
48 & $0.4(0.08)$ & $-0.2(0.08)$ & $<0.001$ & $45 / 51$ & $>99$ \\
60 & $0.4(0.09)$ & $-0.2(0.09)$ & $<0.001$ & $39 / 39$ & $>99$ \\
72 & $0.5(0.09)$ & $-0.1(0.09)$ & $<0.001$ & $32 / 34$ & $>99$ \\
84 & $0.5(0.10)$ & $-0.2(0.10)$ & $<0.001$ & $31 / 31$ & $>99$ \\
96 & $0.6(0.11)$ & $-0.2(0.11)$ & $<0.001$ & $23 / 24$ & $>99$ \\
104 & $0.7(0.12)$ & $-0.4(0.12)$ & $<0.001$ & $18 / 19$ & \\
\hline
\end{tabular}

${ }^{a}$ IRIS $=$ International Renal Interest Society; ${ }^{b}$ LS-Mean = least squares mean; ${ }^{~} S E M=$ standard error of mean.

stage score at each OP compared to baseline. In contrast, controls showed positive change at each OP. The data indicate that treatment significantly lowered disease stage over time.

\section{Treatment and Control IRIS-Stage}

\section{Distribution vs. Time}

At baseline, the control group had a larger proportion of cats classified as IRIS Stage $2(68.4 \%)$ than did the treat ment group (40.3\%). At all subsequent OP the proportion of cats classified as IRIS Stage 2 was greater in treated cats compared with controls, as shown in Figure 5. Controls moved from predominantly Stage 2 to predominantly Stages 3 and 4 at week 104, whereas treated cats moved from a nearly equal distribution between Stages 2 and 3 to mostly Stage 2, with a small percentage of Stage 3 and 4 cats at week 104. Cats returned to IRIS Stage 1 only in the treatment group. Figures 5, 6, and 7 and Table 8 show the distribution of animals in each IRIS stage versus time.

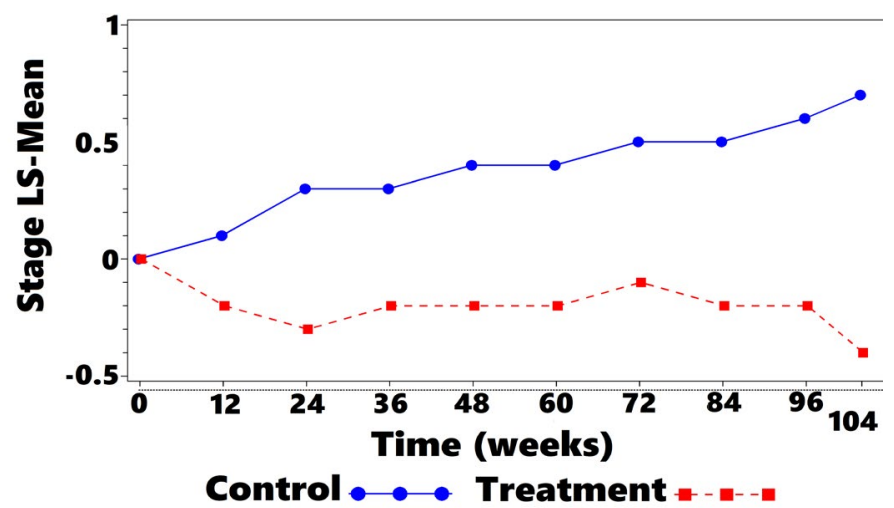

Figure 4: IRIS ${ }^{\mathrm{a}} \mathrm{LS}-\mathrm{Mean}^{\mathrm{b}}$ Stage Change-from-Baseline vs. Time

${ }^{\mathrm{a}}$ IRIS $=$ International Renal Interest Society; ${ }^{\mathrm{b}} \mathrm{LS}-\mathrm{Mean}=$ least squares mean.

June 2019 | Volume 7 | Issue 2 | Page 46

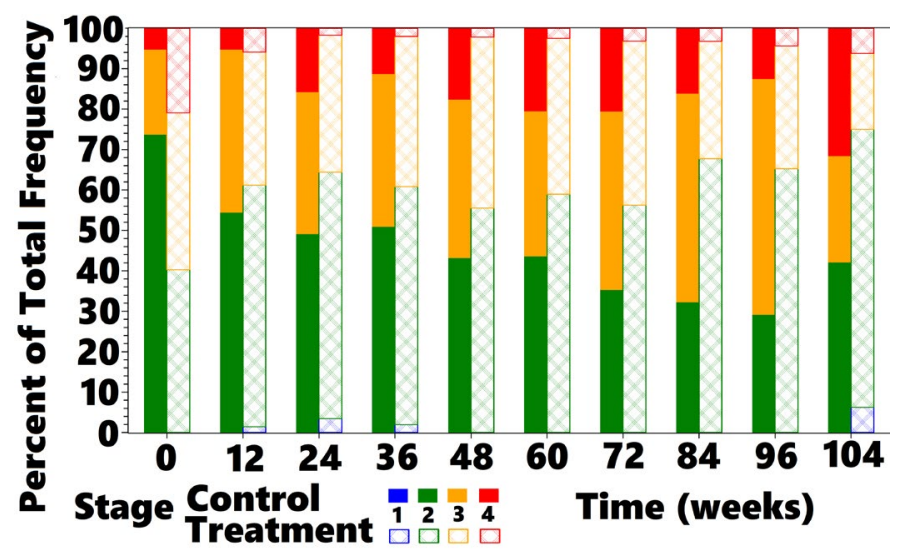

Figure 5: Cumulative IRIS a Stage Frequencies in Treatment and Control Groups vs. Time ${ }^{a}$ IRIS = International Renal Interest Society.

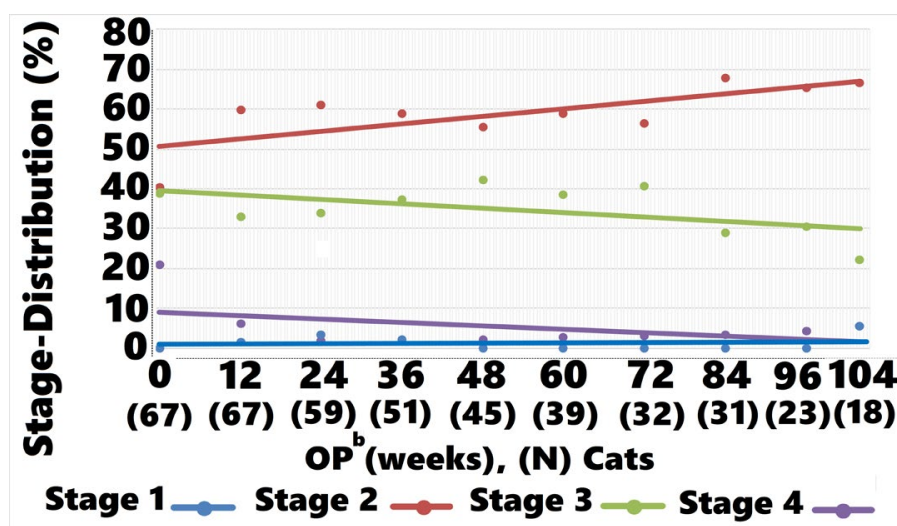

Figure 6: Treatment IRIS a Stage-Distribution vs. Time ${ }^{\mathrm{a}} \mathrm{IRIS}=$ International Renal Interest Society; ${ }^{\mathrm{b}} \mathrm{OP}=$ observation period.

\section{PHOS}

Treated cats showed an overall LS-mean PHOS difference at 104 weeks, when compared with controls, of -0.3 (CI: $-1.2,0.6 ; \mathrm{P}=0.5$; data not shown). However, treatment group mean and median PHOS declined from baseline 
Table 8: Number and Percentage of Cats in IRIS ${ }^{\text {a }}$ Stages per OP

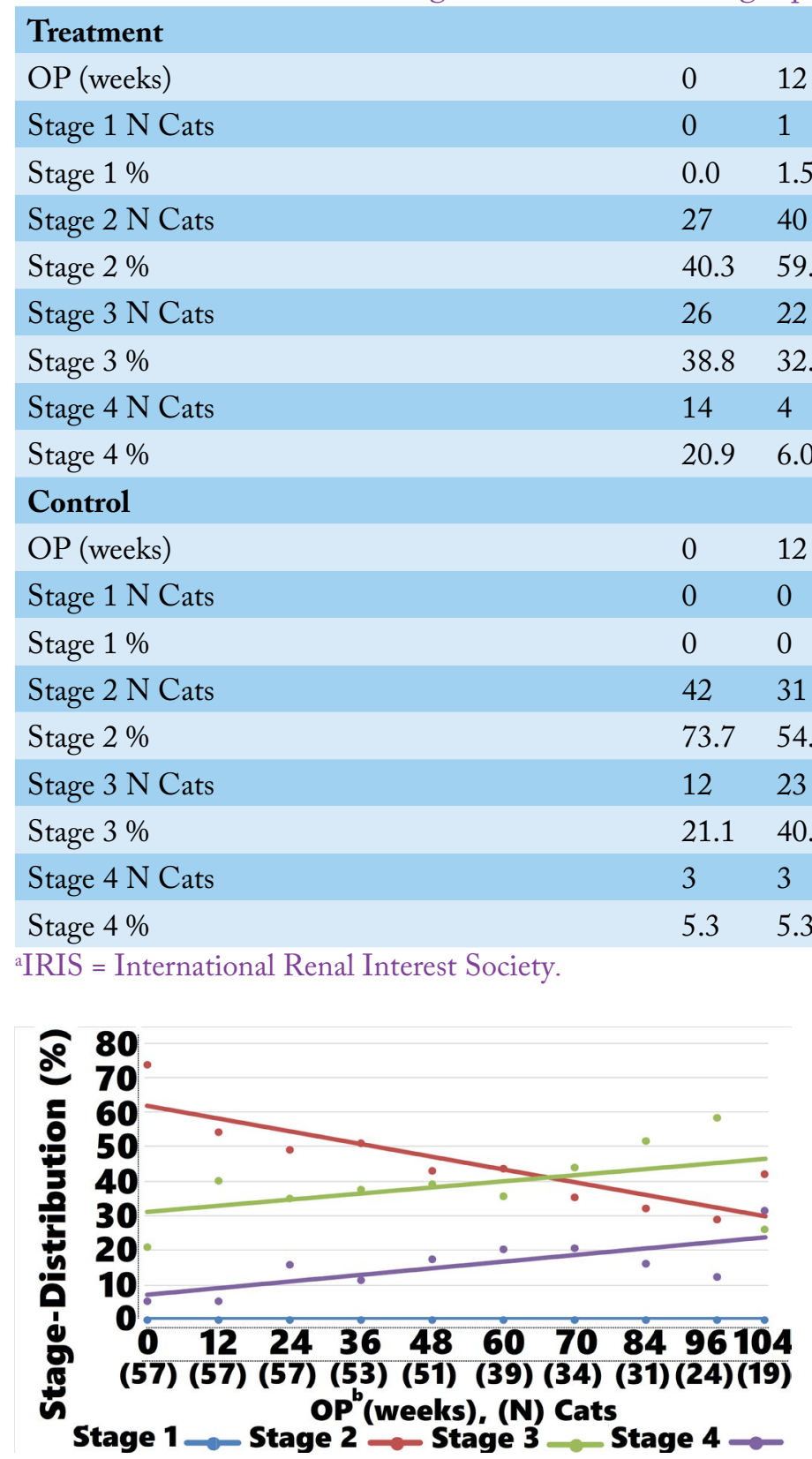

Figure 7: Control IRIS a Stage-Distribution vs. Time

${ }^{a}$ IRIS = International Renal Interest Society; ${ }^{\mathrm{b}} \mathrm{OP}=$ observation period.

-1.3 (CI:-1.11, -1.34, $\mathrm{P}=0.002$ ), and -0.2 (CI: -0.15, -0.25, $\mathrm{P}<0.002)$, respectively, whereas control group mean and median values increased 0.14 (CI: $0.45,0.03, \mathrm{P}=0.004), 0.3$ (CI: 0.20, 0.10, $\mathrm{P}<0.002$, respectively (Figures 8, 9). Mean and median values remained within reference range for both groups through all OPs.

\section{Safety and Palatability}

The cell viability assay revealed no cytotoxicity to $\mathrm{hRPTEC}$ when exposed to $\mathrm{AB} 070597$ for $72 \mathrm{~h}$ at $37^{\circ} \mathrm{C}$, over the concentration range $(100.00,50.00,25.00,12.50,6.25$, $3.13,1.56,0.78,0.39$, and $0.2 \mathrm{ug} / \mathrm{mL}$ ), as shown in Figure 10; therefore, no IC50 was calculated. Treated cats accepted AB070597 as a single oral dose and on food. Treatment

diaries were not used in this study, but there were no reports of digestive distress or diarrhea. Some cats displayed symptoms consistent with CKD, but no observed adverse effects attributable to supplementation were reported by owners or veterinarians. There were no adverse changes in serum chemistries or complete blood counts traceable to supplementation in treated cats (data not shown).

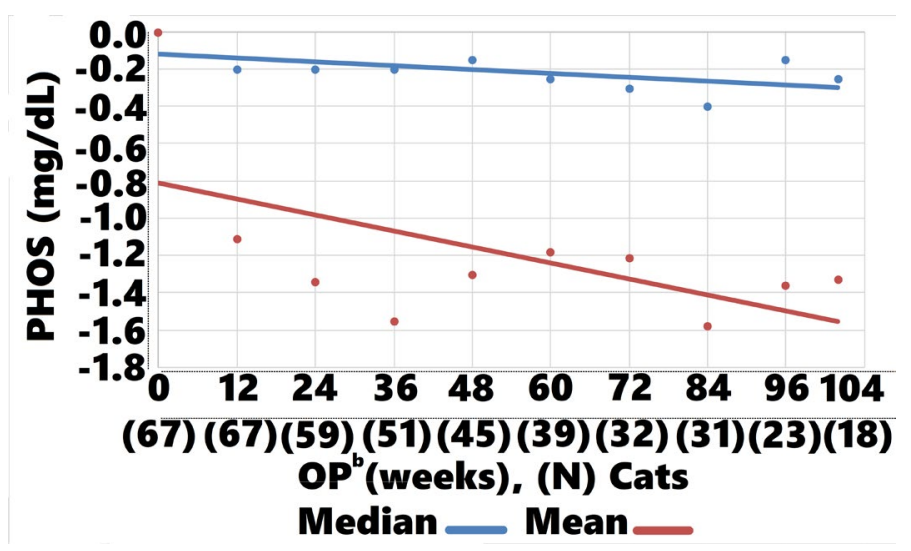

Figure 8: Treatment $\mathrm{PHOS}^{\mathrm{a}}$ Change-from-Baseline vs. Time: Median $(P=0.002)$, Mean $(P=0.002)$ ${ }^{\mathrm{a}} \mathrm{PHOS}=$ blood-serum phosphate concentration; ${ }^{\mathrm{b}} \mathrm{OP}=$ observation period.

\section{Body WeIGHT}

Baseline body weights were recorded in 57 treated cats. Body weights were recorded in 41 of those cats at their final study-related clinic visit. Baseline and time-equivalent 
Table 9: Summary of Body Weights (kg)

\begin{tabular}{lll}
\hline Baseline & Control & Treatment \\
\hline $\mathrm{n}$ & & 57 \\
\hline Mean $\left(\mathrm{SD}^{\mathrm{a}}\right)$ & 53 & $4.1(1.17)$ \\
\hline Median $\left(\mathrm{min}^{\mathrm{b}}\right.$, max $\left.^{\mathrm{c}}\right)$ & $4.5(1.28)$ & $3.9(2.2,7.2)$ \\
\hline Last Clinic Visit & $4.1(2.3,8.4)$ & \\
$\mathrm{n}$ & & 41 \\
Mean (SD) & 46 & $4.1(1.30)$ \\
\hline Median (min, max) & $3.7(1.14)$ & $4.0(1.9,7.7)$ \\
\hline Weight Change-from Baseline to Last Clinic Visit & $3.5(2.1,7.2)$ & 41 \\
$\mathrm{n}$ & & $0.0(0.75)$ \\
\hline Mean (SD) & 45 & $0.0(-1.7,1.3)$ \\
Median (min, max) & $-0.9(1.07)$ & $<0.001$ \\
\hline P-value & $-0.8(-3.2,1.6)$ &
\end{tabular}

${ }^{\mathrm{a}} \mathrm{SD}=$ standard deviation; ${ }^{\mathrm{b}} \mathrm{min}=\operatorname{minimum} ;{ }^{\mathrm{c}} \max =$ maximum

Table 10: Mean BMP-7 mRNA Fold-Change for Concentrations of AB070597 and L-Carnosine Measured by qRTPCR in hRPTEC

\begin{tabular}{|llllll|}
$\begin{array}{l}\text { AB070597 } \\
(\mathbf{u g} / \mathbf{m L})\end{array}$ & MFC $^{\mathbf{a}}$ & $\mathbf{S D}^{\mathbf{b}}$ & $\begin{array}{l}\text { L-carnosine } \\
(\mathbf{u g} / \mathbf{m L})\end{array}$ & $\mathbf{M F C}$ & SD \\
\hline 100 & 3.957982 & 1.532254 & 113.12 & 3.261911 & 1.356335 \\
\hline 50 & 1.612641 & $*$ & 56.56 & 2.409648 & 0.300896 \\
25 & 5.771671 & 3.169783 & 28.28 & 2.153824 & 1.316414 \\
\hline 12.5 & 1.238226 & 0.519722 & 14.14 & 2.128198 & 2.963974 \\
\hline 6.25 & 1.892023 & 1.228735 & 7.07 & 1.443206 & 0.901008 \\
\hline 3.125 & 3.286329 & 2.052426 & 3.535 & 2.364290 & 1.241926 \\
1.56 & 1.451196 & 0.490564 & 1.764 & 2.128385 & 2.012427 \\
\hline
\end{tabular}

${ }^{\mathrm{a}} \mathrm{MFC}=$ mean fold-change; ${ }^{\mathrm{b}} \mathrm{SD}=$ standard deviation; * Zero division error.

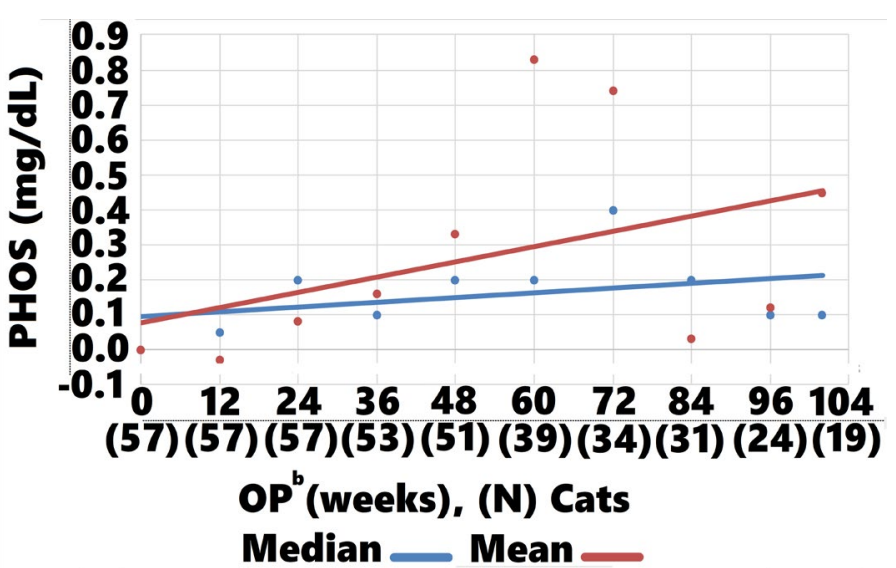

Figure 9: Control $\mathrm{PHOS}^{a}$ Change-from-Baseline vs. Time: Median $(P=0.002)$, Mean $(P=0.004)$. ${ }^{\mathrm{a}} \mathrm{PHOS}=$ blood-serum phosphate concentration, ${ }^{\mathrm{b}} \mathrm{OP}=$ observation period.

body weights were available from medical records for 53 and 46 control group cats, respectively. Control group cats lost an average of $0.9 \mathrm{~kg}(\mathrm{P}<0.001)$, while cats in the treatment group showed a mean body weight change of
$0.0 \mathrm{~kg}(\mathrm{P}<0.001)$. Changes in body weight are shown in Table 9.

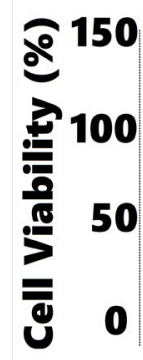

\section{$\begin{array}{lllll}0.20 & 0.78 & 3.12 & 12.5 & 50\end{array}$ 0.391 .566 .2525100 Concentration (ug/mL)}

Figure 10: hRPTEC $^{\text {a }}$ Viability vs. AB070597 Concentration

${ }^{a}$ hRPTEC $=$ human renal primary proximal tubule epithelial cells. 


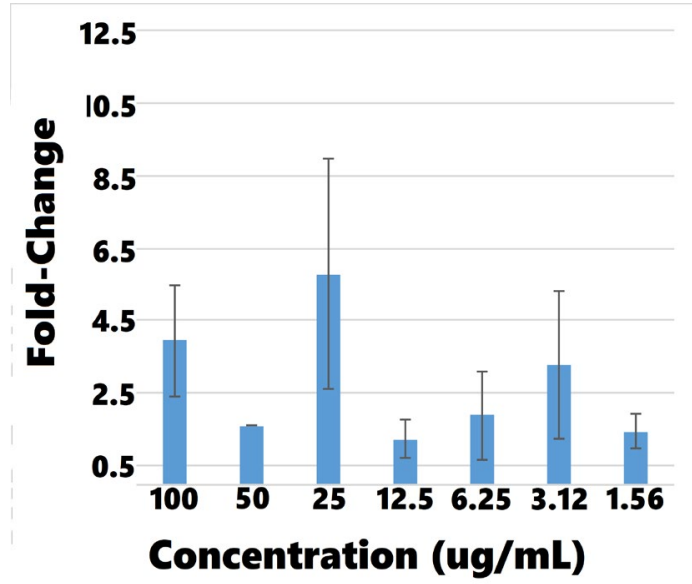

Figure 11: AB070597-Induced Fold-Change in BMP-7 ${ }^{\text {a }}$ mRNA $^{\text {b }}$ in hRPTEC ${ }^{c}$, Measured by qRT-PCR ${ }^{d}$.

${ }^{a} \mathrm{BMP}-7$ = bone morphogenetic protein $-7 ;{ }^{\mathrm{b}} \mathrm{mRNA}=$ messenger ribonucleic acid; 'hRPTEC $=$ human renal primary proximal tubule epithelial cells; ${ }^{\mathrm{d}} \mathrm{qRT}-\mathrm{PCR}=$ quantitative real timepolymerase chain reaction.

\section{BMP-7 MRNA EXPRESSION AsSAY}

Overall, BMP-7 mRNA fold-change increased with rising concentrations of AB070597 and L-carnosine. BMP-7 mRNA was increased and significantly different from controls in all culture wells, except 1 , at all concentrations (P $<0.05$ ) (supplemental data). Changes were small, however, and no significant trend was established. Table 10 and Figures 11 and 12 show the mean fold-change at varying concentrations.

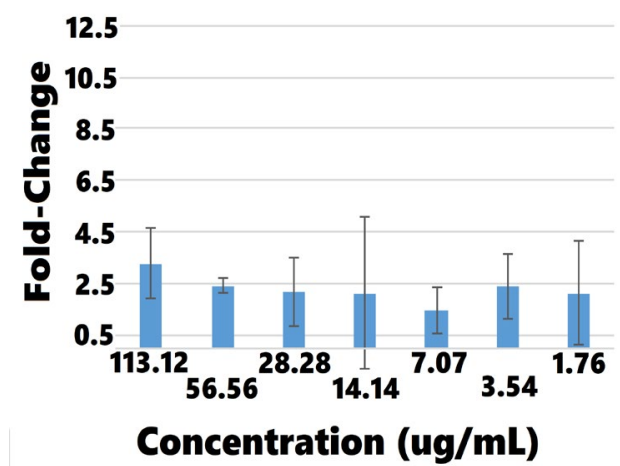

Figure 12: L-carnosine-Induced Fold-Change in BMP-7 ${ }^{\text {a }}$ mRNA $^{\mathrm{b}}$ in hRPTEC ${ }^{\mathrm{c}}, \mathrm{Measured}^{\text {by }}$ qRT-PCR ${ }^{\mathrm{d}}$

${ }^{\mathrm{a}} \mathrm{BMP}-7$ = bone morphogenetic protein-7; ${ }^{\mathrm{b}} \mathrm{mRNA}=$ messenger ribonucleic acid; 'hRPTEC $=$ human renal primary proximal tubule epithelial cells; ${ }^{\mathrm{d}} \mathrm{qRT}-\mathrm{PCR}=$ quantitative real timepolymerase chain reaction.

\section{DISCUSSION}

Current controversy exists over whether TDs provide adequate nutrition for CKD cats (Scherk and Laflamme,
2016). Commercial TDs, with decreased protein, phosphorus, and increased carbohydrate percentages, were not fed in this study because they would have lowered baseline oral amino acid and phosphorus intake and prevented some cats from reaching their daily metabolic energy requirement (Salaun et al., 2017; Hewson-Hughes et al., 2011). SCr was chosen as an indicator of renal function because it correlates strongly with disease severity (Elliott and Barber, 1998). PHOS was selected because increased levels associated with accelerated disease progression and poor prognosis (Boyd et al., 2008). The IRIS disease staging system was used because it is an accepted tool for categorizing disease stage and monitoring progression. Bodyweight was an important variable used as an estimate of protein oxidation and nitrogen balance.

Mean SCr dropped dramatically in treated cats from baseline to week 12 and continued a generally negative slope to week 104. Control cats experienced the opposite trend, with mean $\mathrm{SCr}$ rising from baseline through week 104. Treatment group median body weight, over the same time remained stable, which was likely the result of their diet providing adequate nutrition by not restricting protein and fat. Had treatment cats lost weight, there might be reason to question $\mathrm{SCr}$ improvement, but that was not the case.

There are biological mechanisms that might explain these differences: $\mathrm{SCr}$ correlates positively with increased plasma levels of the endogenous L-arginine derivatives, asymmetrical and symmetrical dimethylarginine, in cats with $\mathrm{CKD}$ (Jepson et. al., 2008). Both competitively block cellular uptake of L-arginine, the exclusive biological substrate for nitric oxide synthesis, thereby inhibiting its production. The pathogenic role of blocked nitric oxide synthesis in human CKD patients was discussed by Zoccali et al. (2001) and Bode-Boger et al. (2006). In diverse models of renal disease, oral L-arginine supplementation consistently improves glomerular filtration rate (Klahr, 1999).

Treatment resulted in significant improvements in mean IRIS stage at week 24 onward. Treatment also created significant improvements $(\mathrm{P}<0.001$, except for week $12[\mathrm{P}$ $=0.006])$ in LS-mean IRIS stage change-from-baseline compared with controls, suggesting that treatment arrested, and to some extent, reversed disease. The reduction in IRIS stages conflicts with those observed in cats treated with conventional therapies, whose stages increase with time.

Mean and median PHOS remained within reference range for both treatment and control groups through 104 weeks. There were, however, significant differences in change-from-baseline, with PHOS falling below baseline from week 12 through week 104 in the treatment group and PHOS rising from week 24 through 104 in con- 
trols (Figures 8, 9). The steady decline in treatment group PHOS might seem unusual, since cats were fed non-protein, non-phosphorous restricted diets. One explanation is that amino acids increase glomerular filtration rate, which would increase phosphate excretion. Another is that cats preferentially use amino acids for gluconeogenesis to maintain glucose needs (Eisert, 2011). The amino acids in AB070597 are gluconeogenic and might have elevated insulin levels in response to increased blood-serum glucose. Increased insulin lowers PHOS by stimulating cellular uptake (Riley et al., 1979). This was observed in humans when circulating L-arginine levels were increased by infusion, resulting in a highly significant fall in PHOS that was significantly correlated to increased insulin (Massara et al., 1980). Finally, increased BMP-7 expression might have played a role in the treatment group's persistent PHOS decline from baseline. BMP-7 gene expression declines in early stages of renal fibrosis and continues to decline with disease progression in the rat model (Xuhua et al., 2007). Gravesen et al. (2018) showed that exogenous BMP-7 treatment created a significant PHOS decrease in CKD rats that had been fed a high phosphorus diet (1.2\%) for 14 weeks. Even though BMP-7 mRNA fold-change was not statistically significant in this study's BMP-7 mRNA expression assay, there was a positive trend with rising AB070597 concentrations. It is possible that increased endogenous BMP-7 expression induced non-functional nephrons to differentiate and regain their normal phenotype, thereby adding to the total functional nephron number, resulting in increased fractional PHOS excretion.

Cats are unable to maintain nitrogen balance when protein intake is below their protein requirement (Green et al., 2008), resulting in negative nitrogen balance and weight loss. Treatment group cats maintained stable mean and median body weight and were not fed TDs, implying that they preserved nitrogen balance as a result of their non-restrictive diets. Diet data was not available from all control-referring clinics, but from clinics that kept diet records, $60.4 \%$ of cats were prescribed TDs, which was $66.7 \%$ of all controls, presenting a possible explanation for the group's significant mean and median weight loss. Freeman et al. (2016), showed that weight loss in CKD cats accelerates after diagnosis, across all IRIS stages, which implies that a common underlying intervention at diagnosis might be responsible (e.g., TD prescription). Markovich et al. (2015) found that $51 \%$ of owners were compliant when TDs were recommended, so it is reasonable to expect that many control cats at clinics that did not have diet records were also fed TDs. Data is convincing, however, that TDs extend survival, but at a cost. Green et al. (2008) showed that when cats were fed low protein TDs, protein oxidation exceeded energy intake by approximately $39 \%$, whereas oxidation and energy intake were adequately matched with medium and high protein diets. Ross (2016) conducted a study, where feeding tubes were placed in $34 \mathrm{CKD}$ cats to control TD intake for long-term body-weight maintenance. Body weight stabilized or increased slightly, despite continued disease progression. Median survival was 178 days, and Kaplan-Meyer survival curves showed that approximately $74 \%$ died within one year. When this current study's results are viewed as a whole, there is reason to hypothesize that weight control and longevity might be enhanced with a normal diet and amino acid/dipeptide supplementation.

\section{CONCLUSIONS}

Treated cats exhibited significant overall reductions in $\mathrm{SCr}$ LS-mean change-from-baseline and IRIS stage compared with untreated controls. Treatment group IRIS LS-mean stage change-from-baseline was negative at each OP, indicating disease stage reduction, whereas control group IRIS LS-mean stage change-from-baseline was positive at each $\mathrm{OP}$, indicating disease stage advance. PHOS changefrom-baseline persistently declined in treated cats and persistently increased in controls, suggesting that treated cats increased fractional excretion, increased glomerular filtration rate, or both. Treated cats maintained body weight, suggesting stable nitrogen balance. Oral supplementation of renoprotective amino acids and dipeptide in AB070597 prevented, and to some extent, reversed disease progression in treated animals that were fed non-protein and non-phosphorous restricted diets. Clinical use of this compound may benefit the greater population of companion cats diagnosed with CKD.

\section{ACKNOWLEDGMENTS}

The author gratefully acknowledges the staff at Whitsell Innovations, Inc. for their assistance with manuscript preparation and to PharPoint Research, Inc. for their expertise and insight with data analysis and figure design. He also acknowledges the professional scientific capabilities of Cyprotex US, LLC staff for their BMP-7 mRNA and cell viability analyses.

This study was made possible by generous support from the John T. Fulton Trust.

\section{CONFLICT OF INTEREST}

The author declares no financial conflict of interest.

\section{REFERENCES}

- Aldini G, Orioli M, Rossoni G, Savi F, Braidotti P, Vistoli G, Yeum KJ, Negrisoli G, Carini M (2011). The carbonyl scavenger carnosine ameliorates dyslipidaemia and renal function in Zucker obese rats. J. Cell Mol. Med. 15(6):1339- 
1354. https://doi.org/10.1111/j.1582-4934.2010.01101.x

- Archer JD (2015). Effect of AB070597 on blood-serum creatinine concentration in cats with chronic kidney disease. Res. J. Vet. Pract. 3(3):58-68. https://doi.org/10.14737/ journal.rjvp/2015/3.3.58.68

- Bode-Boger SM, Scalera F, Kielstein JT, MartensLobenhoffer J, Breithardt G, Fobker M, Reinecke H (2006). Symmetrical dimethylarginine: a new combined parameter for renal function and extent of coronary artery disease. J. Am. Soc. Nephrol. 17:1128-1134. https://doi.org/10.1681/ ASN.2005101119

- Bartges JW (2012). Chronic kidney disease in dogs and cats. Vet. Clin. North Am. Small Anim. Pract. 42(4):669-692. https://doi.org/10.1016/j.cvsm.2012.04.008

- Boyd LM, Langston C, Thompson K, Zivin K, Imanishi M (2008). Survival in cats with naturally occurring chronic kidney disease (2000-2002). J. Vet. Intern Med. 22(5):11111117. https://doi.org/10.1111/j.1939-1676.2008.0163.x

- Caney SM (2017).An online survey of dietary and phosphate binder practices of owners of cats with chronic kidney disease. J. Feline Med. Surg. 19(10):1040-1047. https://doi. org/10.1177/1098612X16672999

- Chakrabarti S, Syme HM, Elliott J (2012). Clinicopathological variables predicting progression of azotemia in cats with chronic kidney disease. J. Vet. Intern Med. 26(2):275-281. https://doi.org/10.1111/j.1939-1676.2011.00874.x

- DiBartola SP, Rutgers HC, Zack PM, Tarr MJ (1987). Clinicopathologic findings associated with chronic renal disease in cats: 74 cases (1973-1984). J. Am. Vet. Med. Assoc. 190(9):1196-1202.

- Elliott J, Barber PJ (1998). Feline chronic renal failure: clinical findings in 80 cases diagnosed between 1992 and 1995. J. Small Anim. Pract. 39(2):78-85. https://doi. org/10.1111/j.1748-5827.1998.tb03598.x

- Elliott J, Rawlings JM, Markwell PJ, Barber PJ (2000). Survival of cats with naturally occurring chronic renal failure: effect of dietary management. J. Small Anim. Pract. 41(6):235242. https://doi.org/10.1111/j.1748-5827.2000.tb03932.x

- Eisert R (2011). Hypercarnivory and the brain: protein requirements of cats reconsidered. J. Comp. Physiol. B. 181(1):1-17. https://doi.org/10.1007/s00360-010-0528-0

- Foster IC, Hernando N, Biber J, Murer H (2006). Proximal tubular handling of phosphate: A molecular perspective. Kidney Int. 70(9):1548-1559. https://doi.org/10.1038/ sj.ki.5001813

- Freeman LM, Lachaud MP, Matthews S, Rhodes L, Zollers B (2016). Evaluation of Weight Loss Over Time in Cats with Chronic Kidney Disease. J. Vet. Intern. Med. 30(5):16611666. https://doi.org/10.1111/jvim.14561

- Gravesen E, Lerche Mace M, Nordholm A, Hofman-Bang J, Hruska K, Haagen Nielsen C, Kjaer A, Olgaard K, Lewin E (2018). Exogenous BMP7 in aortae of rats with chronic uremia ameliorates expression of profibrotic genes, but does not reverse established vascular calcification. PloS One. 13(1): e0190820. https://doi.org/10.1371/journal. pone. 0190820

- Green AS, Ramsey JJ, Villaverde C, Asami DK, Wei A, Fascetti AJ (2008). Cats are able to adapt protein oxidation to protein intake provided their requirement for dietary protein is met. J. Nutr. 138(6):1053-1060. https://doi.org/10.1093/ jn/138.6.1053

- Hewson-Hughes AK, Hewson-Hughes VL, Miller AT, Hall SR, Simpson SJ. Raubenheimer D (2011).Geometric analysis of macronutrient selection in the adult domestic cat, Felis catus. J. Exp. Biol. 214(Pt6):1039-1051. https://doi. org/10.1242/jeb.049429

- International Renal Interest Society (2016).http://www. iris-kidney.com/pdf/3_staging-of-ckd.pdf; accessed 24 May 2018.

- Ito-Kato E, Suzuki N, Maeno M, Takada T, Tanabe N, Takayama T, Ito K, Otsuka K (2004). Effect of carnosine on runt-related transcription factor-2/core binding factor alpha-1 and Sox 9 expressions of human periodontal ligament cells. J. Periodontal. Res. 39(3):199-204. https:// doi.org/10.1111/j.1600-0765.2004.00725.x

- Jepson RE, Syme HM, Vallance C, Elliot J (2008). Plasma asymmetric dimethylarginine, symmetric dimethylarginine, 1-arginine, and nitrite/nitrate concentrations in cats with chronic kidney disease and hypertension. J. Vet. Intern. Med. 22(2):317-324. https://doi.org/10.1111/j.19391676.2008.0075.x

- Kestenbaum B, Sampson JN, Rudser KD, Patterson DJ, Seliger SL, Young B, Sherrard DJ, Andress DL (2005). Serum phosphate levels and mortality risk among people with chronic kidney disease. J. Am. Soc. Nephrol.16(2):520-528. https://doi.org/10.1681/ASN.2004070602

- Klahr S (1999). Can L-arginine manipulation reduce renal disease? Semin Nephrol. 19(3):304-309.

- Markovich JE, Freeman LM, Labato MA, Heinze CR (2015). Surveyofdietaryandmedication practicesofownersofcatswith chronic kidney disease. J. Feline. Med. Surg. 17(12):979-983. https://doi.org/10.1177/1098612X14563097

- Massara F, Martelli S, Cagliero E, Camanni F, Molinatti GM (1980). The hypophosphatemic and hyperkalemic effect of arginine in man.J.Endocrinol.Invest. 3(2): 177-180. https:// doi.org/10.1007/BF03348247

- Mitch WE, Walser M, Steinman TI, Hill S,Zeger S, Tungsanga K (1984). The effect of a keto acid-amino acid supplement to a restricted diet on the progression of chronic renal failure. N. Engl. J. Med. 311(10):623-629. https://doi.org/10.1056/ NEJM198409063111002

- Polzin DJ, Osborne CA, Adams LG, Lulich JP (1992). Medical management of feline chronic renal failure. In: Kirk RW, Bonagura J eds.Current Veterinary Therapy XI. Philadelphia:W.B. Saunders, 848.

- Reyes AA, Karl IE, Klahr S (1994). Role of arginine in health and in renal disease. Am. J. Physiol. 267(3 Pt 2):F331-346.

- Riley MS, Schade DS, Eaton RP (1979). Effects of insulin infusion on plasma phosphate in diabetic patients. Metabolism. 28(3):191-194. https://doi.org/10.1016/00260495(79)90063-5

- Ross S (2016). Utilization of feeding tubes in the management of feline chronic kidney disease. Vet. Clin. North Am. Small Anim. Pract. 46(6): 1099-1114. https://doi.org/10.1016/j. cvsm.2016.06.014

- Sabatino BR, Rohrbach BW, Armstrong PJ, Kirk CA (2013). Amino acid, iodine, selenium, and coat color status among hyperthyroid, Siamese, and age-matched control cats. J. Vet. Intern. Med. 27(5):1049-1055. https://doi.org/10.1111/ jvim. 12165

- Sadar S, Kaspate D, Vyawahare N (2016). Protective effect of L-glutamine against diabetes-induced nephropathy in experimental animal: role of KIM-1, NGAL, TGF- $\beta 1$, and collagen-1. Ren. Fail. 38(9):1483-1495. https://doi.org/10.1 080/0886022X.2016.1227918

- Salaun F, Blanchard G, Le Paih L, Roberti F, Niceron C (2017). 
Impact of macronutrient composition and palatability in wet diets on food selection in cats. J. Anim. Physiol. Anim. Nutr. (Berl). 101(2):230-328. https://doi.org/10.1111/jpn.12542

- Scherk MA, Laflamme DP(2016). Controversies in Veterinary Nephrology: Renal Diets Are Indicated for Cats with International Renal Interest Society Chronic Kidney Disease Stages 2-4: The Con View. Vet. Clin. North Am. Small Anim. Pract. 46(6): 1067-1094. https://doi.org/10.1016/j. cvsm.2016.06.007

- Tada Y, Yano N, Takahashi H, Yuzawa K, Ando H, Kubo Y, Nagasawa A, Uehara S, Ogata A, Nakae D(2008).Toxic effects of L-aspartic acid at high dose levels on kidneys and salivary glands in Fischer 344 rats detected in a 90day feeding study. Food Chem. Toxicol. 46(8):2789-2795. https://doi.org/10.1016/j.fct.2008.05.013

- Watanabe M, Suliman ME, Qureshi AR, Garcia-Lopez E, Bárány P, Heimbürger O, Stenvinkel P, Lindholm B (2008). Consequences of low plasma histidine in chronic kidney disease patients: associations with inflammation, oxidative stress, and mortality. Am. J. Clin. Nutr. 87(6):1860-1866. https://doi.org/10.1093/ajcn/87.6.1860

-Xuhua M, Sen L, Xingyi M, et al (2007). The expression of bone morphogenic protein-7 and its significance in renal tissue of unilateral ureteral obstruction rat model. Sichuan Med. J. 2007-07.
- Yatzidis H (2002). A new, superior, single and stable, amino acid and bicarbonate-based, glucose-free solution for peritoneal dialysis. Dialysis Transplant. 31(3):143-149.

- Yatzidis H (2004). Oral supplement of six selective amino acids arrest progression renal failure in uremic patients. Int. Urol. Nephrol. 36(4):591-598. https://doi.org/10.1007/ s11255-004-8782-2

- Yin M, Zhong Z, Connor HD, Bunzendahl H, Finn WF, Rusyn I, Li X, Raleigh JA, Mason RP, Thurman RG (2002).Protective effect of glycine on renal injury induced by ischemia-reperfusion in vivo. Am. J. Physiol. Renal. Physiol. 282(3):F417-423. https://doi.org/10.1152/ ajprenal.00011.2001

- Zeisberg M, Hanai J, Sugimoto H, Mammoto T, Charytan D, Strutz F, Kalluri R (2003). BMP-7 counteracts TGF-beta1induced epithelial-to mesenchymal transition and reverses chronic renal injury. Nat. Med. 9(7):964-968. https://doi. org $/ 10.1038 / \mathrm{nm} 888$

- Zoccali C, Bode-Boger S, Mallamaci F, Benedetto F, Tripepi G, Malatino L, Cataliotti A, Bellanuova I, Fermo I, Frolich J, Boger R (2001). Plasma concentration of asymmetrical dimethylarginine and mortality in patients with end-stage renal disease: a prospective study. Lancet. Dec 22-29. 358(9299): 2113-7 